\title{
THE MOST FREQUENT TOPICS OF INTEREST FOR SUPPORTIVE CARE (SC) EDUCATION IN THE EASTERN EUROPE AND THE BALKAN REGION (EEBR)
}

\author{
Bakić N1, Dimitrijević J1, Bošnjak $S^{1}$, Žilić $A^{1}$ \\ ${ }^{1}$ Institut za onkologiju i radiologiju Srbije
}

\section{Introduction}

The Second Regional Educational Meeting on SC in Cancer Patients for (EEBR) was held in Belgrade, Serbia (December 1-2, 2017). Topics covered were related to cancer-induced symptoms and treatment-related toxicities with the goal to further promote SC as an integral part of comprehensive cancer care in the region.

\section{Objectives}

To analyze the most preferred topics which would be selected for the agenda of the third regional educational meeting on SC for EEBR (2019)

\section{Method}

By completing the evaluation form participants were asked to name and rank 3 topics they would like to see included in the agenda of the 3 rd regional EEBR symposium. MASCC membership and ESMO booklets were offered for 3 prizes in the raffle. Descriptive statistic methods were used to analyze and identify the most frequent topics of participants interest.

\section{Results}

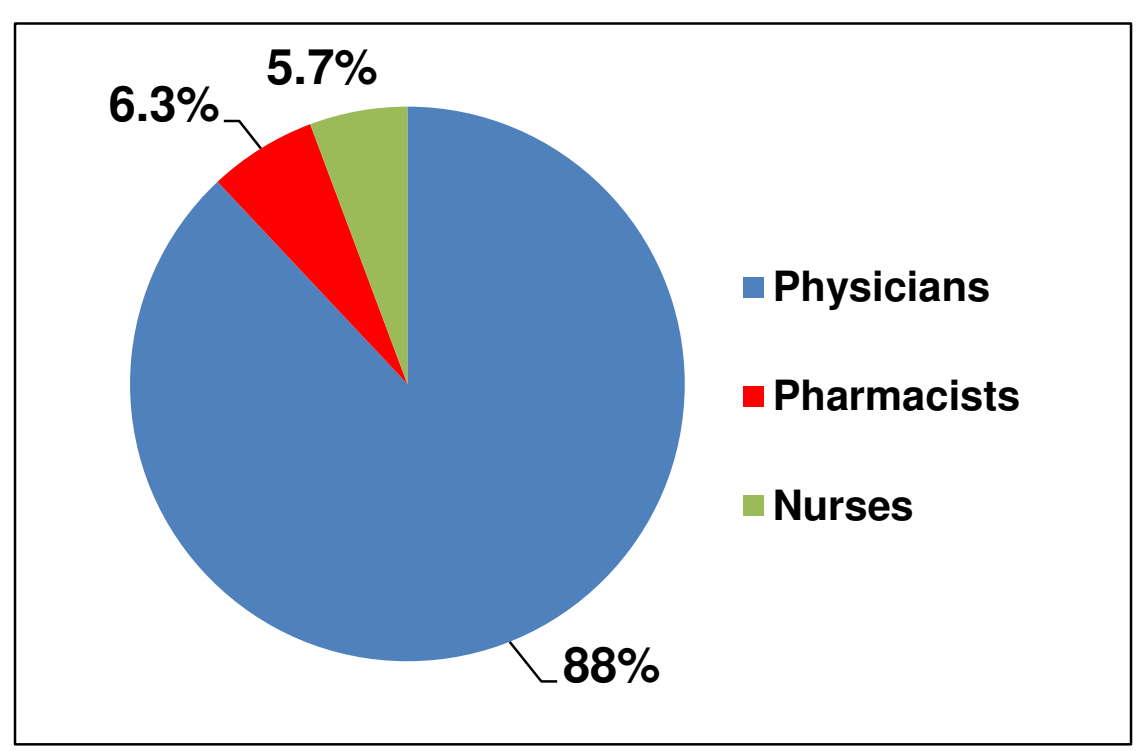

Figure 1. Participants statistics

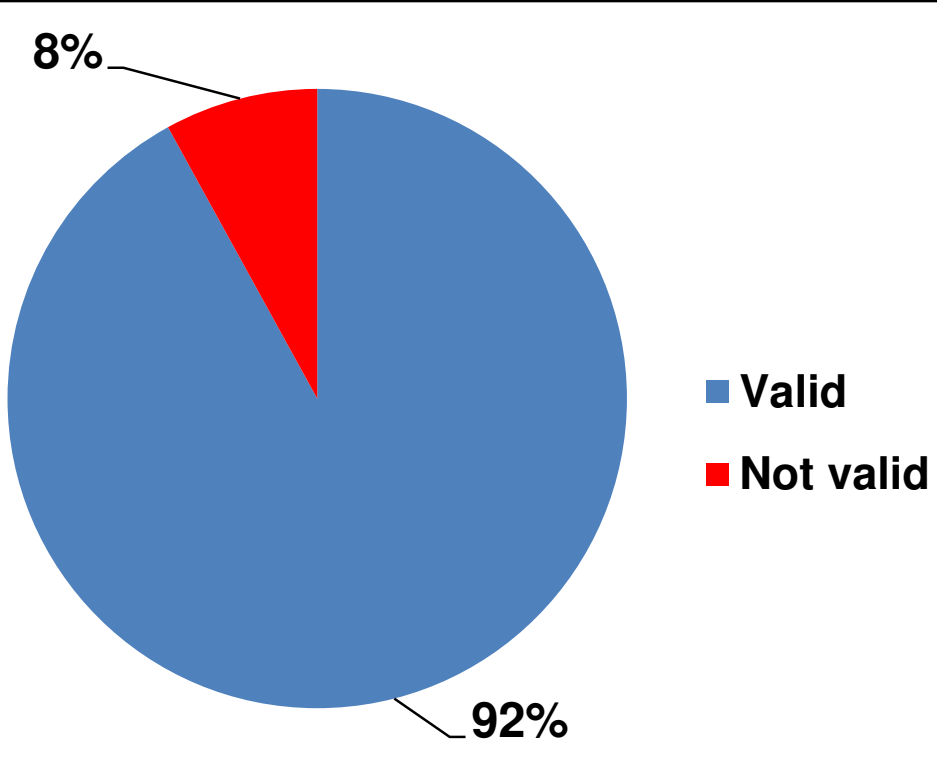

Figure 2. Evaluation form completion

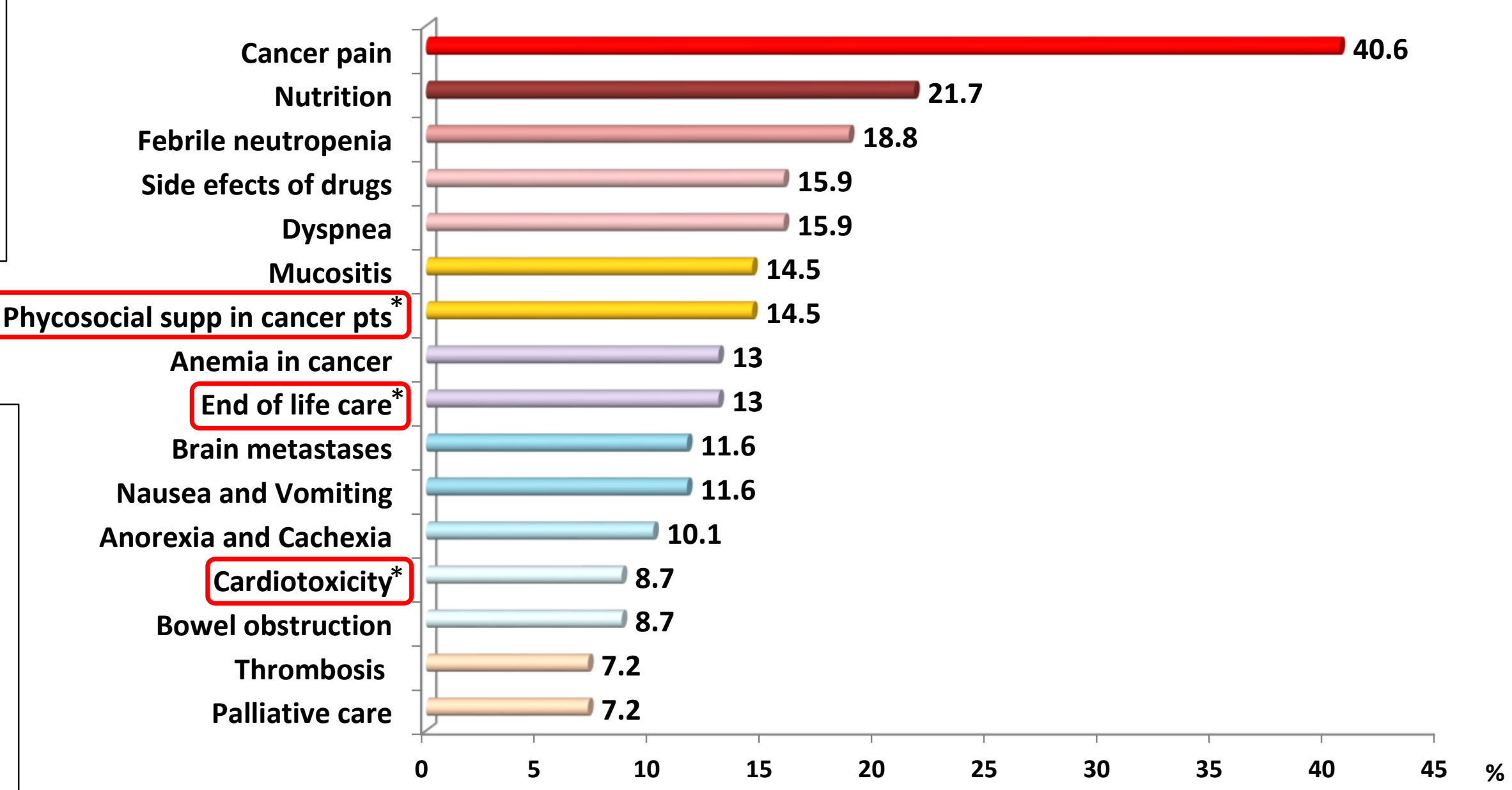

Figure 3. Frequency of topics of interest

* 3 brand new topics

\section{Conclusions}

The raffle offered helped us identify 10 most interesting SC topics. The 3 new topics were identified to be included in the agenda for 2019 meeting therefore these topics will be considered for the next regional meeting agenda. 